\title{
Research on Teaching Strategies of Deep Learning based on the Mobile Internet
}

\author{
Guixin Zhao \\ School of Information \\ Qilu University of Technology \\ Jinan, China \\ email: guixin79@126.com
}

\begin{abstract}
Deep learning is a kind of learning based on the development for understanding higher-order thinking, it is characteristic of Focusing on critical understanding, emphasizing the content integration, promoting knowledge construction, and its application of migration. The teaching strategies to promote the deep learning are proposed based on the analysis of the connotation and characteristics of deep learning and the mobile Internet in the paper. Those strategies include the construction of mobile learning community, designing the appropriate learning resources to stimulate students' deep learning by experience activities and paying attention to the process assessment in the deep learning.
\end{abstract}

Keywords-Mobile Internet; Deep Learning; Teaching Strategies

\section{INTRODUCTION}

Mobile Internet is the combination of the mobile communication and the internet, and also the general term of the practice activities based on the combine of the internet technology, platform, business model and application of mobile communication technology. At the same time, along with the popularity of smart mobile phone and mobile computing technology, more and more people are getting used to all aspects of the work, learning and living knowledge through the mobile Internet, that is a mobile learning [1]. Mobile learning is the application of mobile communication technology and mobile computing technology in the field of education, and provides the strong conditions for today's information age learning and Individual lifelong learning. The learners can make use of the mobile terminal at any time and place (such as mobile phones, smart mobile phone, PDA, notebook computer) to learn. The mobile learning breaks the restrictions of the network learning depending on the "line" or "computer", consequently breaks the limitations of time and space, can provide the learning support for any learners at anytime and anyplace, and meet the learners to acquire any content for any learning desire at anytime and anyplace[2]. Therefore, the characteristics of mobile learning are the relatively large flexibility and randomness, a strong correlation between the situations to be helpful for learners to acquire new knowledge actively, a strong situational relevance which is conducive to learning and acquiring new knowledge actively and powerful interaction which can make learners to use a variety of ways to carry out cooperative learning with all kinds of people in the process of individual research.
However, today when the digital networking, Mobilization and other new learning methods have emerged and began to prevail, the learning efficiency and effect did not have a substantial increase. Even due to misuse of new learning tools and techniques, some learning activities only stay in the shallow level of learning. The network is even considered to be "a hotbed of shallow learning" and is not fit for the deep learning activities [3].This seemingly has certain reality basis, but this is not the nature and destiny of the network learning. In the era of knowledge economy informationization learners are more required to be able to deep-seated knowledge and information, to understand the complex concepts, to grasp the deeper inherent meaning, and then to construct the personalized contextual knowledge system to solve complex problems of reality. Deep learning has become an important and effective way of learning and learning concept under the background of the era, and been caused the widespread concern of the study group and individual learner's attention.

\section{DEEP LEARNING}

\section{A. The connotation of deep learning}

Deep learning [4] is that learners can critically learn new ideas and facts which are put into the original cognitive structure, can communicate in many ideas, and transfer existing knowledge to new situations in order to make decisions and solve the problem of learning on the basis of understanding. It is not only an active, critical way of learning, but also the effective way of meaningful learning. The numerous modern teaching models advocated in the new round of educational reform of our country such as anchored teaching, problem based learning, project based learning, design based learning have the deep learning concept at a certain extent. Shallow learning corresponded with the deep learning is a passive, mechanical way of learning, it is that the information is passively accepted, simple repeated and mechanically remembered as isolated, irrelevant facts. Shallow learning neglects of the deep understanding, deep processing and keeping for a long time of knowledge, and even can't achieve the construction of knowledge, transfer application and problem solving.

From the perspective of learning target, there are the six levels corresponding to "know, understand, application, analysis, synthesis and assessment" according to the classification of learning objectives of Bloom in the cognitive field, the cognitive level of shallow learning only 
staying in the first two levels of "know, understand" ,mainly is the knowledge of the simple description, memory or copy. The cognitive level of the deep learning staying in the after four higher "application, analysis, comprehensive, assessment", not only relates to memory, paying more attention to the understanding and application of knowledge. Therefore, the more intuitive expression is that shallow learning in the low cognitive level , is a low level cognitive skills acquisition involving low order thinking activities; on the other hand, the deep learning in the high cognitive level obtains advanced cognitive skills involving higher order thinking activities. Obviously, the realization of deep learning is closely related to the application of high level thinking. It can be said, the higher order thinking is the core characteristic of deep learning, and the development of high order thinking ability is helpful to realize and promote deep learning. While deep learning is helpful to improve learners' thinking quality and learning efficiency.

\section{B. The features of deep learning}

1) Deep learning focuses on critical comprehension.

Deep leaning is a critical learning based on understanding, and requires learner to keep a critical or skeptical attitude about anything, critically look at the new knowledge and deeper think in order to enhance the understanding of deeper knowledge and complex concept.

2) Deep learning emphasizes the integration of information.

This integration is first multi-disciplinary knowledge and multi-channel information integration; in addition, the integration emphasized by deep learning including the integration of new knowledge and information which advocates to integrates the relate new information with the known concepts and principles into the original cognitive structure, so led to a new understanding of knowledge and information, long-term keep and transfer application. While the shallow learning regards information as an insular unrelated unit to accept and remember, not promote to understand information and knowledge and keep them for long-term.

3) Deep learning promotes the knowledge construction.

In the background of the era of knowledge economy, the learners can not only get the useful information from the massive information, but also to be able to convert the information into knowledge, combine new knowledge with existing knowledge experience, and construct new knowledge based on the existing knowledge structure.

4) Deep learning focuses on transfer application.

Transfer application requires learners to deeply understand the learning situation, judge and grasp of the key elements. So that learners can "infer other things from one fact" in a similar situation and also can analysis and determine the differences in the new situation and transfer the thinking to application.

5) Deep learning is geared to solve the problems.

An important purpose of learning is to solve the complex problems facing the reality. Deep learning requires learners to face and to solve practical problems, otherwise the result of learning is difficult to explicitly proof. In fact the complexity of the problems which we face and need to solve is the embodiment and requirement of deep learning at a certain extent.

6) Deep learning advocates Lifelong learning.

The deep learner will learn knowledge and skills actively in order to meet the needs of their own development, while the shallow learner only completes the task by receiving information passively. In addition, due to the acceleration of the knowledge renewal speed, lifelong learning has become the only way to maintain personal competence, at the same time learners have higher requirements for the depth of learning.

\section{RESEARCH ON TEACHING STRATEGIES OF DEEP LEARNING BASED ON THE MOBILE INTERNET}

Based on the analysis of the characteristics and connotation of deep learning and the characteristics of mobile internet, we propose some teaching strategies to promote deep learning in the mobile Internet environment:

\section{A. Construct the learning community based on mobile Internet}

From the point of science learning, learning should be synergic and based on the group, rather than individual learning and examination. The individual pure learning lacking of social interaction is unable to achieve the real and lasting deep learning. Learners are in a decentralized state in the environment of mobile internet. No other than the construction of the learning community [5] can make Companions to talk to each other, interact and cooperate with each other in order to learn together and share knowledge, and have a more profound, more comprehensive understanding of knowledge [6]. Meanwhile the community can reduce or transfer the Individual cognitive load of the course study, and lead to knowledge migration and knowledge creation. As the saying goes "everyone firewood high flame," the division of labor and the brainstorming in study to improve the efficiency of learning not only can form a comprehensive and systematic understanding of learning materials and learning activities through the collisions of the different ways of thinking and the process of different understanding, but also conducive to the formation of critical thinking and improve the learning ability. This is deep learning. You can use the QQ group or WeChat to form a learning community in the practical applications [8]. Each member can carry out discussion and cooperation, brainstorming, drawing on collective wisdom and absorbing all useful ideas to complete learning tasks, and share of learning experience and learning outcomes, so as to promote students' deep learning.

\section{B. To design the appropriate learning resources}

The randomness of mobile learning time and space leads to the learners not to study deeply. However, teachers can design appropriate learning resources for learners to learn efficiently in free time and space.

1) Design small scale learning materials and take on multi-dimensional teaching content [9]. 
Researches show that people's attention is highly decentralized in the "movement". Learners study in a certain fragmentary time. The various new context brought by the movement is deferent with the fixed large capacity learning style.

Therefore, mobile learning requires small-scale learning materials associated with each other, to decompose knowledge into small but interrelated learning unit in order to make the same course under different themes of fragmented resources to form an organic whole and constitute a learning system through the learning of continuous learning. Learners can learn by using a portable learning tool whenever and wherever possible in fragmentary time. So we should design audio-visual materials which are conducive to learning and enable the learners to focus on learning in the trivial time when learning resources are developed.

2) Design challenging topic of conversation to stimulate students to think

Education experts think that wisdom is more important than knowledge. The real education consists of a habit of thinking and advanced thinking skills. The basic unit of the modern course is the "problem", the primary task of the curriculum reform is to reorganize the curriculum and the design of the problem is the main method of the organization of curriculum content. In mobile learning teachers should reorganize a lot of knowledge and design the question carefully to stimulate the students' body and mind for carrying out inquiry learning, and to understand the knowledge learned deeply in order to promote the development of students' senior thinking ability.

\section{3) Pay attention to guiding design}

The center of mobile learning is learner, but the support role of teachers isn't ignored. In mobile learning process, teachers still have to guide learners' learning with the mobile communication technology, to give them timely and effective support especially when they are in trouble. In the design of teaching content teachers pay attention to add annotation and labels in easy wrong place in order to guide students to learn and use the iconic method properly, to show the details of the operation and to improve the learning effect of students, so as to improve the quality of learning. This requires the teaching platform to support efficient interaction and communication for facilitating the successful completion of the learning.

\section{Stimulate students' deep learning by experience activity}

There is such a paragraph in the learning revolution:" to read the information, we can learn 10 percent; to hear the information, we can learn 15 percent; but to experience, we can learn 80 percent. This paragraph means that experience learning can improve the students' mental models, play their learning potential and effectively change the traditional teaching indoctrination. Generally the experiential learning in higher education has been emphasized in developed countries. Such as the proportion of practice teaching and theory teaching is 3:1 in the high school teaching plan in American; 2:1 in British; 2:1 in German High Commissioner; in France teachers teach each theory lessons equipped with 2
3 experiment course. As we know and identify that Dewey has put forward the famous theory of "learning by doing". He thought that learner must use the practical activity of trying, attempting and reforming to obtain real knowledge. And in Piaget's cognitive theory, he emphasized that the individual could obtain a lot of knowledge coming from sensory experience, and he paid attention to the situation design of the system to let learners learn through their personal experience by being personally on the scene though the creation of learning environment. The sensory involvement of Hands, eyes, ears, nose would produce more specific and explicit moved and understanding, and cause brain thinking.

Teachers should pay attention to Knowledge closely with operation skills in the specific implementation of deep learning. The teaching design is required to resolve and quantify the teaching target to make teaching objectives be clear and refined, not like the traditional network teaching design that are clearly defined of the teaching target in every unit and listed in the course material [10]. That makes the learners not only to comprehend the teaching target of the teaching unit, but also to test really reached the requirements of the teaching goal through practice, test methods.

\section{Pay attention to the process assessment in deep learning}

The continuous deep introspection and assessment [11] and timely feedback on students' learning can enable students to introspect their own learning effectively, adjust the learning methods in time and help students better understand the learning content, so as to realize deep learning in the process of deep learning. A lot of researches have proved that, "an important learning harvest of students stem from often their learning feedback, especially when the feedback contains specific advice which can guide students to make continuous efforts [12]. The feedback will greatly promote students' learning when it pays close attention to the learning process of students rather than the final results. The attention of the process and the task make students to think that their cognitive ability is no longer regarded as everlasting individual characteristics, but is a dynamic development process. This cognition will enable students to regard their current results as a result of their current efforts to learn, and can also cause their next learning motivation as well as keep students self-confidence about learning ability [13]. Therefore, deep learning requires that teachers must attach importance to the value of the process assessment in the students' learning, pay attention to student's learning progress and give timely feedback, then guide students to adjust their learning strategies according to their own learning. At the same time, deep learning also requires that teachers should focus on students' metacognitive ability and the development of the thinking quality in the assessment process. Because the metacognitive ability has been developed and the thinking quality has been improved, these will further stimulate students to study deeply and actively explore and will lead students' learning into a higher level [14]. We can use the electronic performance assessment system (EPSS), electronic portfolio (ELP) etc. in the 
implementation of the process assessment in deep learning. Portfolio can display the effort and progress of every person in the learning process and reflect an aggregation of learning outcomes. It is a kind of assessment based on the process, is a qualitative assessment. Portfolio assessment can record the success and setback in the growth of the students, provide a self-reflection of space for students and enable students to grow mature in their introspection.

\section{SUMMARY}

In the process of the research on the effective teaching strategies promoting deep learning in the mobile internet environment, teachers first build a learning community based on mobile Internet, second design the appropriate learning resources to stimulate the students' deep learning by experience activities, and finally emphasize the process assessment in the process of deep learning pay in order to promote students to learn deeply according to the characteristics of mobile learning. Deep learning has been attached importance to in domestic and foreign and has become a hot issue which everyone concerns in the mobile internet environment. With the development of society, we recognize that it is important to learn how to learn and we need our deep learning rather than shallow learning. We are accomplished at deep learning, so that we can remain invincible in the society been filled with opportunities and challenges.

\section{ACKNOWLEDGMENT}

In this paper, the research was sponsored by the teaching research project of QiLu University of Technology (Project No. 2015024) and by the teaching research project of QiLu University of Technology (Project No. 2013024).

\section{REFERENCES}

[1] Ally, M. Mobile Learning. Transforming the Delivery of Education and Training. Issues in Distance Education series 2009, Edmonton: AU Press.
[2] Motiwalla, L. (2007). Mobile Learning: A Framework and Evaluation, Journal of Computers \& Education, v49, pp 581-596.

[3] Lauren Cifiientes \& Omar Alvarez Xochihua. Learning in Web 2.0 Environments:Surface Learning and Chaos or Deep Learning and Self-Regulation? $[\mathrm{J}]$.The Quarterly Review of Distance Education, 2011,1

[4] Thomas, F. \& Nelson, L. 2005. Deep Learning and College Outcomes: Do Fields of Study Differ?[C] Paper presented at the Annual Meeting of the Association for Institutional Research, May 29 - June 1, San Diego, CA.

[5] Carole Chapman, Leonie Ramondt, \& Glenn smiley. Strong community, deep learning:exploring the link [J]. Innovations in Education and Teaching International, 2005,3(42)

[6] J.J. Vogel-walcutt, J.b. Gebrim,C. Bowers. Cognitive load theory vs. constructivist approaches: which best leads to efficient deep learning? [J], Journal of Computer Assisted Learning, 2011,27

[7] Baeten, Marlies; Kyndt, Eva \& Struyven, Katrien. Using StudentCentred Learning Environments to Stimulate Deep Approaches to Learning: Factors Encouraging or Discouraging Their Effectiveness [J]. Educational Research Review, 2010,5(3)

[8] Jianxia Du, Byron Havard, \& Heng li. Dynamic online discussion: task-oriented interaction for deep learning. [J]. Educational Media International, 2005,3(42)

[9] Thomas F. Nelson Laird*Amy K. Garver. The Effect of Teaching General Education Courses on Deep Approaches to Learning: How Disciplinary Context Matters [J]. Res High Educ, 2010(51)

[10] M. Betül Yılmaz, Feza Orhan. The use of Internet by high school students for educational purposes in respect to their learning approaches [J]. Social and Behavioral Sciences, 2010(2):2143-2150.

[11] Brenda Clare. Promoting Deep Learning: A Teaching, Learning and Assenssment Endeavour[J], Social Work Education, 2007,5(26)

[12] Joshi Mahesh, Babacan Alperhan. enhancing deep learning through assessments: a frameworkfor accounting and law students[J]. Review of Business Research,2009(1):124-131.

[13] Lynch Raymond; McNamara Patricia Mannix; Seery Niall. Promoting deep learning in a teacher education program me through self- and peer-assessment and feedback[J] European Journal of Teacher Education. 2012(2): 179-197.

[14] Zehra Akyol, \& D. Randy Garrison. Understanding cognitive presence in an online and blended community of inquiry: Assessing outcomes and processes for deep approaches to learning [J]. British Journal of Educational Technology, 2011,2(42) 